\title{
Imaginarios geográficos en torno a la franja fronteriza de Tarapacá: el Estado y los habitantes/ migrantes.
}

\author{
Cristian Ovando Santana \\ Universidad Arturo Prat, Chile \\ covando@unap.cl \\ Romina Ramos Rodríguez \\ Universidad Arturo Prat, Chile \\ romina.ramos@unap.cl
}

\begin{abstract}
Imaginarios geográficos en torno a la franja fronteriza de Tarapacá: el estado y los habitantes/migrantes (Resumen)
\end{abstract}

La construcción de múltiples imaginarios geográficos que dan cuenta de la franja fronteriza de Tarapacá, cuestiona el denominado nacionalismo metodológico, que ha caracterizado a los estudios sobre fronteras políticas en América del Sur. Sostenemos que esta frontera se encuentra determinada por diversas y tensas representaciones del espacio surgidas desde actores que la comparten y desde una convivencia histórica transfronteriza que precede a la formación de los respectivos Estado-naciones, que la han delimitado. Por ello, conjeturamos que los habitantes de la frontera tarapaqueña negocian una serie de prácticas e identidades con referencia a lo nacional. Desde esta perspectiva, se constata que convive lo nacional y lo transfronterizo de forma compleja en torno a la redefinición del territorio, registrándose prácticas cotidianas marcadas por la informalidad y su constante trasiego. Éstas conviven con prácticas nacionales que se mueven a través de un discurso potenciado por la seguridad fronteriza y una mirada centrada en velar por la frontera como límite.

Palabras clave: Franja fronteriza-Tarapacá, imaginario geográfico, actores trasfronterizos.

Geographical imagery around the bordering regions of Tarapacá. State, and migrant people (Abstract)

The construction of multiple geographical imagery around the bordering regions of Tarapacá questions the concepts of "methodological nationalism", which has characterized studies about political borders in South America. We define the border through the different actors that share diverse and tense representations of this space, formed also by a historical cross-border coexistence that preceded the formation of the nation-states. Due to that, we surmise that the habitants of the Tarapacá border negotiate a series of practices and identities, maintaining a certain reference to their national ones. From this perspective, we sustain that national and cross-border elements coexist in a complex way, redefining the 
territory, and registering in daily practices marked by informality and the constant border activity. These coexist with nationalpractices, channelled through a discourse that is strengthened by border security issues, and the view of the border as a limit to be safeguarded.

Key words: bordering regions of Tarapacá, geographical imagery, cross-border actors.

La región de Tarapacá ${ }^{1}$, se enmarca dentro de la triple frontera andina que abarca el Sur del Perú, el Norte grande de Chile y el Centro Oeste de Bolivia. Se trata de una zona rural de altura ocupada mayormente por poblaciones aymaras (140.000 aproximadamente, 77\% en Bolivia, $13 \%$ en Perú y $10 \%$ en Chile). Su situación socio-económica resulta de procesos similares de marginalización dentro de sus Estados respectivos. El comercio y las fiestas populares han sido los principales nexos de vida social transfronteriza desde el siglo XIX ${ }^{2}$. Los altos índices de pobreza en las comunidades aymaras de Perú, Bolivia y Chile, su condición de marginalidad, la expulsión de su población joven, la existencia de municipios con escasos recursos operativos, carencia de servicios básicos de salud y educación, la falta de caminos pavimentados, la pérdida de la lengua vernácula, el deterioro de la producción agropecuaria, etc. ${ }^{3}$, se han transformado en una problemática siempre vigente en la franja fronteriza de Tarapacá. En efecto, como veremos más adelante, las redes en torno al municipalismo aymara son una respuesta a esta situación ${ }^{4}$.

Por otro lado, esta región ${ }^{5}$, en tanto entidad social-espacial, está ubicada en el extremo norte de Chile, dentro de sus características destaca constituirse como un territorio marginal, ubicado muy distante de su centro político. Por tanto, ha padecido un histórico sentimiento de abandono y relegación, que se traduce en un sentimiento de alienación territorial. Estos procesos de alienación territorial "implican una integración subordinada de sus espacios socio-territoriales

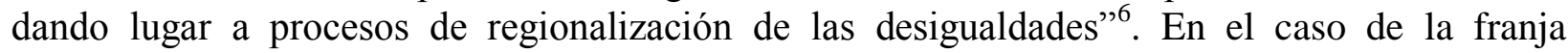
fronteriza de Tarapacá, al igual que toda zona anexada tardíamente al territorio nacional, primero, se encontró subordinada a un Estado nación en consolidación que, desde una representación espacial oficial, impuso y normalizó un espacio fronterizo, caracterizándolo como conquistado, vacío y desprovisto de toda sociabilidad que no fuere promovida por dicha ocupación ${ }^{7}$. Seguidamente, a mediados del siglo XX, se vio afectada por un Estado desarrollista que no consideró sus particularidades territoriales y subjetividades al momento de implementar una serie de estrategias de desarrollo, además de continuar reforzando aquella representación oficial del espacio marcada por una memoria colectiva en torno a la chilenización del Norte Grande y todo lo que conlleva en cuanto a barrer con toda representación que escapase a los cánones de lo nacional ${ }^{8}$.Y, hoy en la actualidad, producto de la emergencia de proyectos

${ }^{1}$ La región de Tarapacá tiene una población levemente superior a los 300.000 habitantes (Censo 2012), en su gran mayoría concentrada en las comunas de Iquique y Alto Hospicio (juntas congregan al 87,8\% de los habitantes). Del total regional, $17,7 \%$ se considera perteneciente a algún pueblo indígena-se identifican 9 pueblos-y de estos $66,8 \%$ son Aymara, 18\% mapuche y 5,8\% quechua. En la comuna de Colchane, la población alcanza apenas las 1300 personas, $96 \%$ de estas son aimaras (Informe INDH).

${ }^{2}$ Rouviere, 2009.

${ }^{3}$ González, et al, 2008, p. 39.

${ }^{4}$ Este artículo es el resultado del Proyecto Anillos SOC 1109, CONICYT, Chile: "Relaciones transfronterizas entre Bolivia y Chile: Paradiplomacia y prácticas sociales 1904-2004".

${ }^{5}$ En adelante, el concepto región lo utilizaremos como sinónimo de la organización social territorial. Si bien reconocemos la distinción de lo físico-espacial de lo social-espacial, en cuanto al tratamiento del concepto región, por tratarse de una aproximación en clave fenomenológica, adherimos a la noción social espacial.

${ }^{6}$ Machado, 2009, p.77.

${ }^{7}$ Nuñez et al, 2013.

${ }^{8}$ En efecto, "tras la crisis del salitre hasta mediados de los años treinta la institucionalidad estatal en materias de estímulo a la producción en la provincia [de Tarapacá] giró, exclusivamente, en torno al resurgimiento de dicha industria. En la práctica, desde la ocupación de Tarapacá el Estado orientó sus iniciativas a intereses ligados al salitre, 
transnacionales que tienen impactos en su dinámica territorial en la medida que facilitan la movilidad de capitales y definen nuevas territorialidades con sus consecuentes nuevas ordenaciones en el ámbito político, social y económico ${ }^{9}$, en la medida que las empresas en torno a la gran minería "construyen estrategias de toma de posición dentro de los mecanismos de gobernación territorial de los lugares en los que invierten ${ }^{10}{ }^{11}$. Además, dichas estrategias se ven reforzadas por el rol del Estado en torno a la seguridad y control de esta región fronteriza.

Estas formas normalizadoras del espacio, históricamente, han promovido valores y normas que en general afectan y han afectado las formas de sociabilidad previa y paralela a la emergencia de lo nacional como demarcador, delimitando y afectando al sentido que cada actor le da al espacio habitado y transitado. Nos referimos particularmente a los habitantes aymaras de dicha franja fronteriza y a los cruzadores de frontera, como veremos a lo largo del trabajo. En respuesta a esta imposición de sentido, como hemos dicho, en estas fronteras complejas surgen procesos de alienación territorial, los que "suscitan la movilización de crecientes fracciones poblacionales que - desde la puesta en juego de sus propias estrategias de sobrevivencia- emprenden nuevos antagonismos en torno a la resignificación de sus territorios" ${ }^{\prime 12}$, respondiendo de distintas formas a la invasión de sus espacios intersubjetivos de cotidianeidad por parte de autoridades públicas, ya sea por la vía de la resistencia, contestación o adaptación a estas nuevas pautas de convivencia.

Actualmente, del mismo modo, los compromisos internacionales suscritos por Chile en materia comercial $^{13}$ y política lo obligan a repensar la seguridad de territorios considerados críticos en la medida que, con algunas de sus prácticas cotidianas, ponen a prueba su estabilidad y prestigio, redundando en su atractivo para la inversión extrajera ${ }^{14}$. Así es como ha apostado por nuevas

(...). En otras áreas de eventual desarrollo, en cambio, los estudios, exploraciones o desarrollo de infraestructura quedaron limitados a subvenciones esporádicas, optando más bien por otorgar concesiones al sector privado.(Donoso 2009, p. 3). Seguidamente, en la década de 1940, el Instituto de Fomento Minero e Industrial de Tarapacá, creado después de la crisis del 30 y como antesala a la CORFO, con el afán de promover desde Santiago estrategias de desarrollo industrial, llego a ser considerado, "el compendio de todos los males de la política de mediados de siglo, y en el principal obstáculo del progreso regional (Donoso, 2009, p. 8). Por su parte, ya en la década de 1970, a partir de la regionalización con un criterio geopolítico: "la primera región paso adquirir características de no región , con un profunda discontinuidad espacial, enormes disparidades internas producto de las políticas que representan el “ interés superior de la nación”, desaprovechamiento de sus aptitudes económicas naturales, con serios vacíos en la configuración de una cultura regional y la carencia de una historia común que permita la identificación de la población con su territorio" (Camus y Rosenblit,2011, p. 68)

${ }^{9}$ Hevilla y Zusman, 2007.

${ }^{10}$ Amilhat Szary, 2013, p. 225.

${ }^{11}$ Por ejemplo, la gran minería participa activamente en varias comisiones dentro de los comités de frontera (Amilhat Szary, 2013:225), instancias de colaboración política transfronteriza entre entidades públicas de dos países, que gestiona las fronteras de chile con sus países vecinos en ámbitos como policías, aduana, turismo, fitosanidad, etc.

${ }^{12}$ Machado, 2009, 77.

${ }^{13}$ Tarapacá tiene una destacada proyección marítima que la vincula al mercado del Asia Pacífico, lo que la hace sea considerada una puerta de entrada para el mercado del Centro Oeste sudamericano (Centro Oeste de Bolivia, Paraguay, Norte de Argentina y Brasil). Esta proyección hacia los mercados internacionales, en el caso de la región de Tarapacá, se debe a que Chile desde 1975 realizó una profunda transformación en su modelo de desarrollo, pasando de uno de sustitución de importaciones a un modelo neoliberal ortodoxo; un proceso de regionalización que promovió la inversión extranjera a través de una serie de medidas como fue decretar la Zona Franca en 1975. En síntesis, se trató de "la aplicación [en el ámbito local] de nuevas reglas económicas, que dejan a cada parte del país libre de valorizar sus "ventajas comparativas" en los mercados mundiales" (Amilhat Szary, 1997, p.59).

${ }^{14}$ Chile, desde 1974 con la promulgación del decreto $\mathrm{N}^{\circ} 600$ estimuló sostenidamente la inversión extranjera otorgando facilidades sobre todo a la inversión de la gran minería transnacional. Se considera un mercado abierto atractivo para la inversión extranjera directa consolidado en las últimas décadas con la firma de 56 tratados de libre comercio. 
tendencias globales tendientes a la seguritización ${ }^{15}$ de los territorios, afectado algunas prácticas sociales propias de la franja fronteriza y sobre todo reforzando la vigencia que presentan imaginarios territoriales estatales basados en escalas monopolizadoras.

Complementando lo recién expuesto, debemos considerar que la región de Tarapacá históricamente ha sido un territorio con una fuerte presencia estatal y militar. Surge como una región conquistada militarmente, por tanto padece los efectos de guerras, asonadas fronterizas ${ }^{16}$ y dispositivos nacionalizadores como fueron la educación fiscal, ${ }^{17}$ las fiestas religiosas y políticas $\operatorname{asistencialistas}^{18}$. También ha estado sometida a la presencia de doctrinas militares con aprehensiones hacia las zonas contiguas, en el marco de la dictadura militar que apeló al nacionalismo con una particular fijación hacia las fronteras contiguas y sus habitantes ${ }^{19}$.

Cabe mencionar que además la frontera entre Chile y Bolivia fue delimitada por el Tratado de Paz y Amistad en 1904. Para entender la complejidad de muchos de los procesos en curso, vale la pena mencionar brevemente algunos hitos históricos que han marcado una serie de desencuentros que tienen su origen en las consecuencias de Guerra del Pacífico (1879-1884) y en el tratado recién señalado que puso su fin ${ }^{20}$. Actualmente, todavía se buscan, sin encontrar éxito, soluciones políticas a este conflicto, a tal punto que en 2013 Bolivia interpuso una demanda en contra de Chile en la Corte Internacional de Justicia de la Haya enmarcada dentro de las fallidas negociaciones históricas emprendidas entre ambos países para dar solución a su enclaustramiento $^{21}$. Este conflicto diplomático si bien no ha afectado la dinámica transfronteriza chileno boliviana, si puede señalarse que ha trabado algunas iniciativas. Es el caso de la realización del XIII comité de integración y frontera Chile- Bolivia, agendado para noviembre de 2013 y suspendido indefinidamente por el gobierno boliviano.

Estos hitos se enmarcan dentro de la historia de la estructuración fronteriza de la mayoría de los Estados Sudamericanos, en los cuales se dio un proceso a mediados del siglo XIX que definió el contenido de sus políticas exteriores hacia las fronteras. Estas estrategias estuvieron marcadas

${ }^{15}$ Dammert y Bailey, 2005

${ }^{16}$ En 1879 tras iniciarse la Guerra del Pacífico pasa a ser temporalmente territorio chileno; ya en 1929 tras tratado bilateral, se anexa definitivamente. En 1975, El presidente de Perú, Velasco Alvarado, en el marco de una de las mayores crisis internas de su mandato producto de que el gasto militar se había hecho socialmente insoportable y la unidad de las Fuerzas Armadas se resquebrajaba, preparaba una invasión para recuperar Arica. En 1979, en el marco del centenario de la Guerra del Pacífico, también se temió una invasión peruana a Arica; esta vez estaba encabezada por el gobierno de Belaunde Terry.

${ }^{17}$ González, 2002.

${ }^{18}$ Fernández, 2009.

${ }^{19}$ En efecto, en la región de Tarapacá en la década de 1980 el curriculum educativo diseñado por la dictadura militar considera la educación fronteriza, la cual expresamente tenía por objetivo inculcar los valores y tradiciones patrias a los habitantes de la franja fronteriza, junto con integrarlos de acuerdo a los fines y objetivos definidos por el Supremo Gobierno (Van Kessel, 1990, p. 12-14). Aún más, la escuela normalista que le precedió se considera un dispositivo chilenizador afincado en Tarapacá (González, 2002). En retrospectiva, "Hasta la década de los 30 el Estado chileno extiende un proceso de asimilación para asegurar su dominio geopolítico de los territorios del extremo norte. Posteriormente se da inicio a un ciclo de políticas asistencialistas que se verán acentuadas con la dictadura militar (1973-1989), para asegurar la retención de población como ejercicio de soberanía territorial.(Fernandez,2009)

${ }^{20}$ Chile, Perú y Bolivia se enfrascaron en una guerra (1879-1183) a causa de territorios mal delimitados tras los procesos de independencia de España y por la existencia de riquezas mineras (salitre) en los territorios en disputa. Dentro de sus consecuencias, Chile se apropia de provincia costera boliviana, dejándola si acceso al mar, y firma tratado en 1904 que le concede libre tránsito por dichos territorios

${ }^{21}$ La demanda boliviana se funda en las expectativas incumplidas por Chile, debido a que a través de actos unilaterales ha ofrecido una salida al mar para Bolivia en varios episodios del siglo XX sin concretarlos. Apela al moderno derecho internacional que considera los derechos expectaticios como fuentes jurídicas de las cuales emanan obligaciones entre las partes. 
por “...la imagen de que en la historia de la estructuración fronteriza del país éste habría sido amputado por un vecino agresivo y expansionista",22.

Figura 1.Mapa de la Franja Fronteriza Tarapaqueña

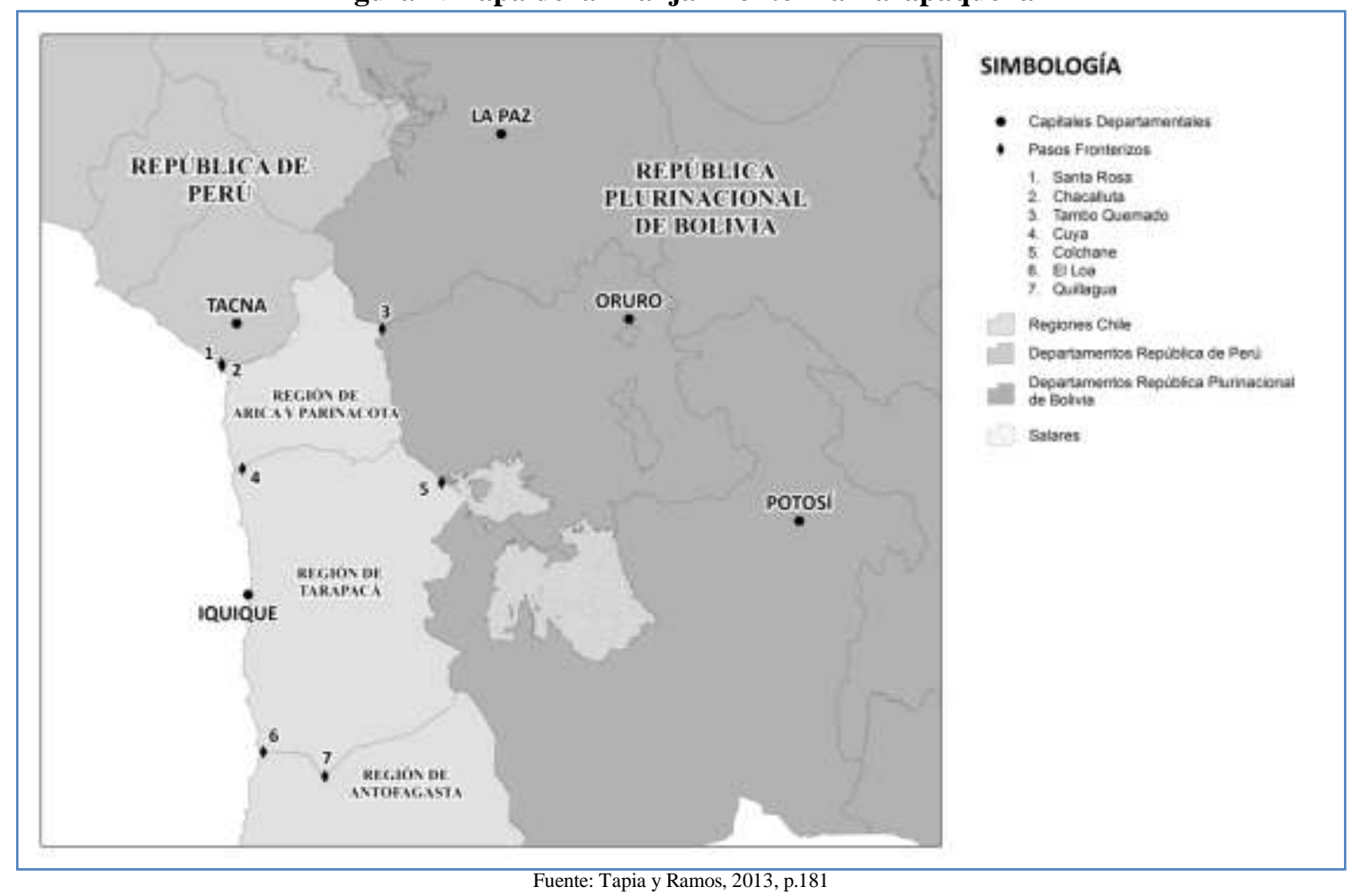

Para el mismo autor, "cuando en la segunda mitad del siglo XX eclosionaron los problemas limítrofes como la cuestión central en las relaciones bilaterales, se había formado una imagen del vecino ya anclada en una conciencia historiográfica. ${ }^{23}$ Para el caso de Bolivia y Chile esta afirmación es categórica, pues la Guerra del Pacífico y sus décadas siguientes constituyen el acontecimiento que termina por construir y consolidar la identidad nacional chilena en oposición a la boliviana ${ }^{24}$. Así, dichas identidades han estado marcadas por la demanda marítima boliviana, la que ha dado contenido a los discursos donde el más contrapuesto ha sido el concepto de "usurpación" por parte de Bolivia y de "reivindicación" por parte de Chile. En síntesis, estos acontecimientos del XIX han "influido directamente en que después de una determinación conflictiva de las fronteras, haya habido una persistente percepción del otro como enemigo, alimentada por la chilenización (...) de los espacios conquistados y dejando abierto el trauma boliviano por la pérdida del acceso al Océano Pacífico"25.

Una de las principales consecuencias de estos procesos a efectos de esta investigación es la vigencia de la denominada territorialización dura; ésta, referida a la delimitación de una espacialidad homogeneizadora, apunta a la existencia en las franjas fronterizas, de controles fronterizos, límites jurisdiccionales, y un interés por la integridad territorial y los derechos

\footnotetext{
${ }^{22}$ Fernandois y León, 2005, p. 96.

${ }^{23}$ Fernandois y León, 2005, p. 96.

${ }^{24}$ Fernandois, 2004.

${ }^{25}$ Rouvière 2009.
} 
soberanos de manera que la división entre actores que están dentro y fuera de la comunidad ("nosotros" y "ellos") están en principio bien definidos. ${ }^{26}$

A partir de estos procesos vemos como paulatinamente durante las últimas tres décadas, el espacio fronterizo tarapaqueño se ve imbuido en realidades múltiples con sus propias valoraciones sobre el espacio. Estas van desde un Estado que vela por su seguridad y desarrollo con una herencia nacionalista que perdura, hasta una comunidad local y migrante de carácter histórico que habita la frontera prescindiendo de alguna manera de aquella, junto a nuevos actores vinculados a la minería transnacional ${ }^{27}$.

Con todo, surge dentro de sus contornos una superposición de imaginarios sociales que desplazan las fronteras de este espacio complejo, donde habitan y deambulan actores que en ocasiones desafían la territorialización estatal. Esta aseveración se funda en que la franja fronteriza tarapaqueña, al igual que toda frontera compartida por dos o más nacionalidades, ve circular "personas, bienes y significados cuya dirección, intensidad y sentido varían según las épocas, las estaciones, los cambios de moneda, los regímenes aduaneros, las políticas comerciales de los países que convergen en ella" ${ }^{28}$.

La frontera tarapaqueña, desde mediados del 2000, comienza a ser conocida a través de los medios de comunicación a partir del constante trasiego por el "Paso Colchane" 29 . La frontera comienza a identificarse con atributos que la asocian con un extendido contrabando y el narcotráfico $^{30}$, se considera además una frontera con una presencia estatal fuerte en torno a barreras fitosanitarias y aduaneras ${ }^{31}$. Por otro lado, se la vincula con un espacio tradicional, marcado por el habitar transfronterizo de comunidades locales ${ }^{32}$ y municipios rurales, con una extendida red de relaciones transfronterizas emprendidas en pos de su desarrollo ${ }^{33}$; también se relaciona con una espacialidad particular, marcada por la continuidad territorial binacional ${ }^{34}$; finalmente, debemos mencionar el constante trasiego de migrantes fronterizos que van dejando su huella como portadores de territorio ${ }^{35}$.

En este sentido, cabe mencionar que la frontera tarapaqueña es considerada una de las fronteras chilenas con mayor tránsito migratorio en la actualidad ${ }^{36}$. Y, aunque su migración ha tenido un carácter histórico constante, en la actualidad se caracteriza por una población que cruza la frontera identificada con motivos principalmente económicos pero sin mayor interés por el asentamiento definitivo $^{37}$; más bien la migración fronteriza en Tarapacá es de periodos cortos lo que permite a los migrantes trasfronterizos realizar viajes de "ida y vuelta" y no interrumpir lazos- culturales y familiares- con las ciudades de origen. Para estos casos, se va construyendo un imaginario geográfico de la frontera que identifica unos límites propios de un Estado territorializado, que permiten distinguir un "nosotros" y "ellos" alterando la condición objetiva y

\footnotetext{
${ }^{26}$ Bialasiewicz, 2005.Citado por Eskelinen, 2011, p.125.

27 Leiva, 2009; Amilhat Szary, 2013.

${ }^{28}$ Giménez Beliveau, 2011, p.8.

${ }^{29}$ Ver figura 1, paso fronterizo $\mathrm{N}^{\circ} 5$.

${ }^{30}$ Corder y Ruiz-Tagle, 2013.

${ }^{31}$ Ovando, Álvarez, 2011.

32 Tapia y Ramos, 2013.

${ }^{33}$ Rouviere, 2009.

${ }^{34}$ Tapia y Ovando 2013.

${ }^{35}$ Ramos y Urbina, 2012; Tapia, 2012.

${ }^{36}$ Tapia, 2012.

${ }^{37}$ Ramos y Urbina, 2012.
} 
subjetiva entre el ciudadano y el extranjero en un breve desplazamiento entre cada estado nación $^{38}$

Con todo, las interacciones entre los diversos actores que habitan y circulan en el espacio tarapaqueño, nos demuestran que en la frontera se construyen una realidad histórica-cambiante. No obstante, como hemos dicho más arriba, pese a la pluralidad de actores e imaginarios espaciales presentes en este espacio, debemos tener en cuenta la construcción de representaciones desde la hegemonía y uniformidad, a partir del peso de los imaginarios nacionales ${ }^{39}$. Éstos se inspiran en mitos fronterizos -en clave turnereana- en torno a su origen nacional moderno a través de la conquista y la ocupación ${ }^{40}$, para nuestro caso, por ejemplo, el referido al descampado de Atacama ${ }^{4 I}$ y sus décadas posteriores tras la Guerra del Pacífico y la ocupación de Tarapacá. También se vincula a la vigencia de antiguas estructuras socioculturales, como es el caso de una frontera en transición desde aquella marcada por la seguridad nacional y la geopolítica tradicional hacia la preeminencia del desarrollo de regiones contiguas ${ }^{42}$.

Dicho lo anterior, nuestra intención es indagar e interpretar sobre esta pugna por la significación del espacio, cuestión que nos permitirá problematizar "la vigencia que presentan imaginarios territoriales basados en escalas monopolizadoras en detrimento de una multi-territorialidad basada en la historicidad particular de regiones periféricas" ${ }^{\prime 4}$.El objetivo de este trabajo es interpretar cómo piensan la frontera y cuál es el contenido de los imaginarios geográficos que exponen algunos habitantes presentes en la franja fronteriza tarapaqueña, particularmente el Estado representado por funcionarios y, paralelamente, habitantes y migrantes que forman parte de estos asentamientos. Conjeturamos que actualmente la presencia estatal, reeditada por la seguridad en torno al contrabando y el narcotráfico, ha tendido a transformar la organización espacial de las relaciones sociales en que se desenvuelven los espacios locales tarapaqueños, dando lugar a la proliferación de múltiples estrategias de adaptación y resistencia ante estos procesos de reconversión territorial. Por ello tomamos en cuenta el sentido que le atribuyen al territorio los habitantes fronterizos en la medida que se resisten o adaptan a estas estrategias. En suma, abordaremos los problemas políticos de la franja fronteriza de Tarapacá, junto con los problemas administrativos que presenta para la administración chilena, la presencia de una identidad de la sociedad de Tarapacá distinta a la estatal, nos referimos a los habitantes y migrantes de dicha franja.

Con el propósito de comprender el significado atribuido por los sujetos estudiados a su propia cotidianeidad, la metodología de análisis que utilizaremos se basa en la interpretación de fuentes primarias: prensa, relatos etnográficos, entrevistas, entre otros. Analizaremos el material empírico recogido, referido al caso abordado: el estado y los habitantes/migrantes de la franja fronteriza de Tarapacá, cotejándolo con la literatura sobre imaginarios geográficos.

\footnotetext{
${ }^{38}$ Alburquerque, 2012, p. 187.

${ }^{39}$ Giménez, Beliveau, 2011; Nuñez et al, 2013.

${ }^{40}$ Brenna, 2011.

${ }^{41}$ Se conocía como un territorio sin vida y presencia humana, ubicado en el extremo norte de Chile, abarcando desde Tarapacá hasta el desierto de Atacama. Se constituye como un mito nacional, ya que se estimaba que en esta zona no existía la posibilidad de habitar y menos de construir una idea de sociedad. Este mito se destruye debido a la instauración de la sociedad del salitre (González, 2013).

42 Ovando, 2012.

${ }^{43}$ Núñez, 2012.
} 


\section{Marco teórico}

\section{Respuestas al nacionalismo metodológico}

Por un lado, constatamos la presencia de un discurso oficial dominante que tiende a la monopolización (nacionalización) del imaginario espacial y a la construcción de unas instituciones, prácticas y dispositivos que reproducen dicho discurso, centrado en velar por la seguridad de la frontera, junto con responder a la normalidad que requieren los flujos de capitales internacionales que circulan en la región. Por otro, destacamos la presencia de un discurso cotidiano y subalterno desde las prácticas que los habitantes conforman, que a menudo son considerados transgresoras del orden fronterizo impuesto desde la otra vereda. Al frente de esta última, encontramos migrantes y habitantes que no forman parte de estos circuitos económicos y que exponen una multi-territorialidad basada en la historicidad particular de esta región ${ }^{44}$, marcada por una notoria continuidad transfronteriza.

En consecuencia, apreciamos cierta tensión entre la superposición de territorios a los que se les da un significado distinto y contradictorio según cada actor. Entendiendo por territorio, a lo largo de este escrito, desde una doble dimensión: "un espacio geográfico material, constituido de diversos lugares agregados y estructurados, y también una construcción social, un sistema de valores que otorga a cada uno de los componentes de este espacio sentidos múltiples y combinados" ${ }^{\circ 5}$.

A partir de este alcance, pretendemos problematizar la noción de frontera construida desde el nacionalismo metodológico, arraigada en las ciencias sociales chilenas, confrontándola con la perspectiva de frontera como un espacio de amplitud variable donde los actores ponen en juego una serie de sentidos y significados a su habitar/ transitar ${ }^{46}$. Este trabajo, toma posición por esta última perspectiva, puesto que consideramos que el nacionalismo metodológico consagra "la tendencia a aceptar al Estado-nación y sus fronteras como un elemento dado en el análisis social" $"$. El sustrato epistemológico que subyace en esta definición concibe a los países como unidades estancas que equiparan la sociedad al Estado-nación ${ }^{48}$. En cambio, cada vez más se considera la mirada desde "abajo hacia arriba" que recoge las experiencias individuales y las formas en que las fronteras impactan en las prácticas diarias de las personas que las habitan ${ }^{49}$.

El nacionalismo metodológico, por tanto, perpetua la frontera como compartimiento cerrado, como un espacio escindido por cada Estado nación, silenciando una serie de procesos y prácticas transfronterizas presentes en el territorio. No obstante, desde una perspectiva fenomenológica, esta naturalización de la frontera ${ }^{50}$ no tiene nada de natural, surge de "artificios simbólicos e imaginarios a través de los códigos y las normas jurídicas, la cartografía del espacio y de las representaciones de mapas ${ }^{51}$. En respuesta, "la geografía política ya no se interesa sólo por los territorios de los Estados nacionales, o por los territorios permanentes, sino también por las territorialidades móviles, temporarias y de límites elásticos" ${ }^{\$ 2}$. Por ello, adherimos a que las

\footnotetext{
${ }^{44}$ Nuñez, 2012.

${ }^{45}$ Debuyst, 2009:21

${ }^{46}$ Giménez, 2009.

${ }^{47}$ Wimmer \& Schiller, 2003, p.576.

${ }^{48}$ Tapia, 2012, p. 3.

${ }^{49}$ Newman, 2006, p. 143.Citado por Tapia, 2012, p.4

${ }^{50}$ Hevilla y Zusman 2008

${ }^{51}$ Alburquerque, 2012, p. 186.

${ }^{52}$ Benedetti, 2014, p. 14
} 
"fronteras, en tanto componentes del territorio, también deberían considerarse como entidades geohistóricas que se transforman de manera permanente a partir de las prácticas sociales. ${ }^{53}$

\section{La representación del espacio a partir de los imaginarios geográficos}

En las franjas fronterizas, en tanto “... zonas territoriales de amplitud variable que se extienden a uno y otro lados de la línea fronteriza, dentro de las cuales la gente negocia una variedad de comportamientos y sentidos asociados a la pertenencia de sus respectivas naciones o estados" "54, se despliegan identidades nuevas y viejas en contacto. Esta posibilidad de cambio está dada si la concebimos desde una aproximación fenomenológica que apunta a la construcción de la representación del espacio; es decir, desde un proceso cognitivo que implica la elaboración de imágenes mentales que otorgan significación a los lugares en el marco de una red de lugares ${ }^{55}$.

Así es como adherimos a "una epistemología para la geografía que tome en cuenta la subjetividad como elemento clave en la diferenciación espacial, una diferenciación que tiene que ver con las formas de imaginar el medio, de aproximarse y actuar en él"," en la medida que "la imaginación es una facultad a partir de la cual se puede otorgar sentido a las acciones, a los pensamientos y a las materialidades pretéritas, siempre permeadas por las visiones del presente" ${ }^{, 57}$. Aunque estas representaciones resultado de esta imaginación "son asimiladas e internalizadas por grupos que hacen diversos usos de ellas, asumiendo cierto acuerdo tácito

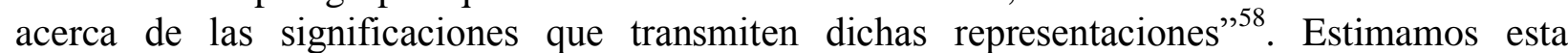
afirmación es clave para comprender la presencia de imaginarios que se reiteran y se tornan como sentidos predominantes que definen e imponen una territorialidad hegemónica ${ }^{59}$, como veremos más adelante.

Ahora, cabe preguntarnos ¿Cómo surge esta representación del espacio? Es el resultado de "acciones, estrategias y dispositivos que colaboran a que la memoria social se afiance como sujeto que define los imaginarios o, simplemente lo real""60. Así, dichos imaginarios son "el resultado de prácticas, diplomacias, artes y tácticas que se despliegan en una historicidad que les otorga sentido"61.

Estas prácticas y dispositivos dan por resultado una memoria colectiva que nos permite comprender las distintas actitudes entre antiguos y nuevos habitantes de un determinado espacio, entre nuevos cruzadores del mismo y los anteriores, entre nuevos actores económicos y los de siempre. Lo relevante es que cada uno de ellos valoriza de manera distinta o similar escenarios, recursos y formas de vida según su experiencia y posición en las relaciones de poder que surgen en dicha construcción en un momento dado.

En suma, el espacio real es resultado de nuestra propia interpretación colectiva, en la medida que nuestra memoria colectiva le asigna el estatus de verdaderos a dichos espacios a partir de ciertos contextos sociales $^{62}$, toda vez que la memoria es el cauce de la personalidad, de la permanente

\footnotetext{
${ }^{53}$ Benedetti, 2014, p. 15

${ }^{54}$ Giménez, 2009, p. 23.

${ }^{55}$ Bailly, 1985. Citado por Zulman, 2013, p. 53.

${ }^{56}$ Zusman, 2013, p. 53.

${ }^{57}$ Zusman, 2013, p. 53.

${ }^{58}$ Lois, 1999

${ }^{59}$ Hevilla y Molina, 2010

${ }^{60}$ Núñez, et al: 2013, p. 114-115.

${ }^{61}$ Núñez, et al: 2013, p. 114-115.

${ }^{62}$ Núñez, et al: 2013, p. 111.
} 
identidad del yo a través de todas las circunstancias cambiantes que se van sucediendo ${ }^{63}$. Este proceso de mediación está sujeto a ciertas convenciones histórico culturales ${ }^{64}$, que en el caso de los espacios fronterizos nacionales se trata de una representación monopólica, que busca proyectar los límites del Estado y la distinción entre nosotros y los otros, los que están fuera y dentro $^{65}$. Pero dada la movilidad de las imágenes colectivas que proyectamos, se construyen nuevos territorios que se resisten a ser aprehendidos por esa memoria oficial. Por tanto, debemos tener en cuenta que la movilidad lleva una huella de otros espacios y como las personas se posicionan en ese espacio, responde a procesos socio-históricos, dejando entrever que la presunta idea de que hay un "supuesto espacio que corresponde habitar" se vuelve falaz ${ }^{66}$.

\section{Conciencia espacial: relaciones entre espacio y trayectorias}

Para complementar esta aproximación, a continuación profundizamos en los imaginarios geográficos. Para David Harvey, la imaginación geográfica o conciencia espacial es entendida como la forma de atribuirle un significado particular al espacio habitado. Nos "permite comprender el papel del espacio (...) en las "transacciones entre individuos y organizaciones" ${ }^{67}$.Así, ésta "contribuye a que el sujeto comprenda su vínculo con acontecimientos y lugares próximos o más distantes". A su vez, puede hacer un uso creativo del espacio y "apreciar el significado de las formas espaciales creadas por otros" $"$. Pero también, desde la destrucción creativa $^{69}$, una perspectiva espacial particular puede barrer con las territorialidades existentes, para instalar nuevos modos de organización política, económica o cultural ${ }^{70}$, según sus motivaciones del momento, la herencia y los cambios del entorno. Estas nuevas modalidades pueden instaurar nuevos límites y nuevos contornos, desafiando las espacialidades que le preceden.

En suma, cada grupo escoge una determinada trayectoria espacial según la propia construcción de su imaginación geográfica o conciencia espacial, nutriéndose ésta de varias dimensiones: objetos, al pasado o a lo desconocido, a la idiosincrasia, a la posición en las relaciones de poder, etc. Por trayectoria espacial, nos referimos a determinadas- y no otras - transacciones entre individuo y organizaciones que suponen proyectos vitales y que ponen en juego el bienestar de las personas ${ }^{71}$. Se trata de establecer "las relaciones entre forma espacial, significado simbólico y comportamiento espacial" ${ }^{\text {72 }}$.

Por otro lado, es admisible considerar que cada grupo define su propia espacialidad, su propio proyecto espacial, imposibilitando el consenso y tendiendo muchas veces al conflicto. Así, bajo la compresión espacial, las distintas significaciones otorgadas al espacio por distintos actores sociales entran en conflicto. Este conflicto se expresa en la lucha por la apropiación y dominación de espacios ${ }^{73}$.

${ }^{63}$ De Castro, 2001.

${ }^{64}$ Es el caso del proceso denominado chilenización de Tarapacá y sus consecuencias en la formación de las identidades locales.

${ }^{65}$ Núñez, et al: 2013, p. 112.

${ }^{66}$ Mendiola, 2012, p. 3.

${ }^{67}$ Harvey, 1985, p. 17.

${ }^{68}$ Harvey, 1985, p. 17.

${ }^{69}$ Harvey, 1985.

${ }^{70}$ Hevilla y Zusman, 2007.

${ }^{71}$ Zusman, 2013.

${ }^{72}$ Harvey, 1985, p. 26.

${ }^{73}$ Mancano, 2012. 
Con todo, consideramos frontera como un espacio cambiante donde se desenvuelven actores con distintas posiciones en tanto se desenvuelven desde relaciones de poder asimétricas ${ }^{74}$. En ella, además, confluyen identidades nacionales, regionales, transfronterizas y nuevas identidades transnacionales. Cada una tiene su propia representación del espacio a partir de su particular conciencia espacial. En ésta, como consecuencia, - sobre todo conjeturamos cuando la idiosincrasia $^{75}$ en términos de memoria colectiva tiene una particular aprehensión por hegemonizar una imagen por sobre otras- deviene una pugna entre una representación del espacio oficial, impuesto por los respectivos Estado naciones, y los espacios de representación construidos por una gama de actores sociales, subalternos ${ }^{76}$. Es el caso de los migrantes fronterizos tarapaqueños que tienen una mirada del espacio y una identidad resultado de sus cambiantes trayectorias espaciales ${ }^{77}$.

Así, las áreas fronterizas son el lugar donde las identidades dominantes (El Estado y el tránsito de capitales) luchan por mantener incuestionada su hegemonía, mientras que las identidades subalternas luchan por el reconocimiento social ${ }^{78}$ porque, como dice Bourdieu, "existir socialmente es también ser reconocido, y por cierto ser reconocido como distinto" ${ }^{79}$.En efecto, consideramos que a partir del poder ejercido desde la hegemonía estatal en el espacio social tarapaqueño, existe cierta resistencia por parte de los que habitan este espacio. Ésta se manifiestan alrededor de prácticas del poder que cruzan todo el tejido social de los diversos actores que comparten el territorio (redes migratorias trasfronterizas, comités de frontera, habitantes de la franja, etc.). Estas prácticas, a su vez, se muestran efectivas cuando se concretan a través del ejercicio de dispositivos insertos en dicho tejido; como por ejemplo las prácticas securitarias ${ }^{80}$, que no dejan de generar conflicto en las relaciones sociales de la franja fronteriza tarapaqueña.

De este modo, el territorio que comprende dicha franja es el espacio apropiado por determinadas relaciones sociales que lo producen y, a su vez, lo mantienen desde formas de poder. El territorio es, al mismo tiempo, una convención y una confrontación. Precisamente porque el territorio

\footnotetext{
${ }^{74}$ Mancano, 2012.

75 Por ejemplo, como es el caso de Tarapacá, una idiosincrasia puede estar marcada por la denominada territorialización dura propia de las fronteras en transición. Por esta última nos referimos a las que han experimentado procesos de largo repliegue e incipiente apertura. Sobre todo a procesos que han tenido consecuencias estructurales: los efectos de guerras fronterizas, presencia de doctrinas militares con aprehensiones hacia las zonas contiguas, presencia de regímenes militares que apelan al nacionalismo, etc.

${ }^{76}$ Lefebvre, 1974.

${ }^{77}$ Tapia y Ramos, 2013.

${ }^{78}$ Por tanto , cabe preguntarnos cómo se forman identidades en espacios conflictivos, como es el caso de las franjas fronterizas donde chocan lealtades nacionales, regionales, transfronterizas y extranjeras; o de otra forma, dónde conviven adscripciones identitarias de base territorial y transnacional; es decir, cómo se forman identidades donde se convive bajo el principio de la imposibilidad estructural de consensuar principios normativos de lo político (Nieto,2011) Por tanto, ¿hasta qué punto podemos aceptar visiones conflictivas y diversas del mundo en estas comunidades? Para responder a esta pregunta es clave comprender que para la concepción agonística de la convivencia democrática entendida como la constitución conflictiva de un espacio simbólico compartido, hay una concepción relacional de la identidad y la subjetividad(Nieto,2011): Podemos aceptar esta diversidad y conflictividad implícita teniendo en cuenta que las identidades se forman y mantienen en contraste con identidades alternativas donde el establecimiento de una identidad implica crear espacio social y conceptual para que ésta identidad exista en formas que chocan con los espacios disponibles a otras posibilidades. La constitución de identidades siempre implica la exclusión de algunas identificaciones para proveer espacio de identificación a otras (Connolly, 1991, p. 160).Así, una política de la identidad en zonas de frontera debe considerar un trazado en que conviven conflictivamente identidades nacionales regionales, transfronteriza desde pluralismo radical.

${ }^{79}$ Bordieu1980:66 citado por Giménez, 2009.

${ }^{80}$ Rodrigues, 2013
} 
posee límites, posee fronteras, es un espacio de conflictualidades" ${ }^{\text {81 }}$. Su configuración como territorio se refiere a las dimensiones de poder y control social que les son inherentes. Ese control se ejerce desde "sus formas e instituciones más regionales, más locales, sobre todo allí donde, saltando por encima de las reglas de derecho que lo organizan y lo delimitan, se extiende más allá de ellas, se inviste en instituciones, adopta la forma de técnicas y promociona instrumentos de intervención material" ${ }^{82}$.

\section{Los actores de la franja fronteriza y su conciencia espacial}

En la franja fronteriza tarapaqueña es posible apreciar -con una intención analítica y acorde a esta investigación- la presencia de dos grupos culturales con sus respectivas conciencias espaciales y trayectorias superpuestas en un territorio conflictivo: el Estado con sus estrategias de gubernamentalidad local y nacional en torno a la seguridad ${ }^{83}$ y los habitantes y cruzadores de la frontera. Un tercero serían los actores transnacionales en torno a la minería, los cuales no tratarán debido a la extensión que implicaría considerarlos.

\section{Habitantes y cruzadores de la frontera}

Es un rasgo habitual en Tarapacá la presencia de extranjeros de origen fronterizo, especialmente bolivianos que habitan Pisisga Bolívar y Oruro $^{84}$. Los censos advierten que el peso de extranjeros limítrofes respecto de la población total de Tarapacá ha sido significativo y mayor al porcentaje nacional $^{85}$. Por tanto, es posible afirmar que, dada la naturaleza fronteriza de la región y la constante interacción de las poblaciones contiguas, lo transfronterizo ha sido un fenómeno permanente y constitutivo de la realidad tarapaqueña.

En cuanto a su conciencia espacial y trayectorias, destacamos, por un lado, las prácticas informales como valor que orienta los intercambios transfronterizos, los vínculos entre habitantes de uno y otro lado de la frontera, entre los habitantes y organizaciones gubernamentales y las propiamente locales. Este se refleja en el contrabando fronterizo ${ }^{86}$, sobre todo de mercaderías provenientes de la Zona Franca de Iquique y en las constantes fricciones entre comerciantes y la presencia estatal en la frontera. En consecuencia, esta tensión redunda en que los "espacios de intercambios "reales" por oposición a los intercambios "legales" se superponen a las mallas del Estado. Dentro de estos espacios, los comerciantes estiman que no son ilegales sus negocios, pese las coacciones jurídicas que la frontera impone sobre los

\footnotetext{
${ }^{81}$ Mancano, 2012, p. 3.

${ }^{82}$ Foucault, 1992, p. 142.

${ }^{83}$ Camaño, 2012.

${ }^{84}$ Pisiga limita con con Chile (Colchane), es el paso fronterizo entre ambos países y pertenece al Departamento de Oruro. Su población se estima en 5 mil habitantes aproximadamente; esta se dedica a la crianza de camélidos y al comercio informal con Chile. A su vez, Oruro es la capital del Departamento y tiene una población de 264.943 habitantes según 1 Censo Nacional de 2012.Además de la agricultura y la minería, el comercio con Chile, particularmente desde la Zona Franca de Iquique, Chile, es una de sus principales actividades económicas.

${ }^{85}$ Tapia, 2012.

${ }^{86}$ Para Bolivia, Desde el año 2000, la importación de mercancías de contrabando representa cerca del $40 \%$ de las importaciones legales para una suma de 700 millones de dólares anuales. la mayor parte proviene de los puertos de Arica e Iquique así como de la Zona franca de Iquique (30\%). (...) Son artefactos como ropa y vehículos usados, aparatos electrónicos, artículos del hogar, los medicamentos, etc. (Judge, 2007, p. 86).
} 
intercambios" ${ }^{\prime 87}$. El siguiente relato refleja con cierta claridad esta práctica habitual, junto con destacar el abandono como una de las razones que estimula el contrabando:

"Hacia la izquierda, a poco más de 50 metros del paso, un camino paralelo se dibuja en el desierto. Es la ruta de los contrabandistas, que a diario, y en forma constante, comercializan productos entre el poblado boliviano de Pisiga Bolívar y Colchane. Tubos de gas, bolsas con mercadería, bidones con gasolina envueltos en bolsas de malla plástica, verduras y bebidas gaseosas son algunos de los productos que van y vienen, durante el día y la noche, desde el pueblo fronterizo."Y es lógico, si en Colchane no se puede comprar ni un pedazo de pan. Los niños no comen dulces, porque no hay negocios, y lo único que quieren es que llegue el domingo para atravesar", agrega el funcionario aduanero" ${ }^{\$ 8}$.

Por otro lado, en el marco de la informalidad señalada, también destacamos la existencia de ferias binacionales de productos agropecuarios y de otra índole a través de actividades comerciales que reflejan una vida cotidiana marcada por desestimar las fronteras políticas. Así mismo, esta informalidad en tanto orienta estrategias de sobrevivencia ${ }^{89}$, refleja uma respuesta al abandono que sufren debido al distanciamiento de sus respectivos Estados. Estos elementos se evidencian en siguiente relato:

"Colchane no es más que un grupo de casas al final del altiplano chileno. El pueblo se sostiene por el pastoreo de llamas y la plantación de quínoa, cebollas y papas. La calle principal es la carretera que llega hasta a Bolivia, donde se alinean la municipalidad, el liceo, el retén y un par de hoteles. El aislamiento se siente en temas como la electricidad, la que únicamente se da entre las 20 horas y la medianoche a través de generadores. La gente se abastece de mercadería al otro lado, en Pisiga Bolívar, [Bolivia] que es tres veces el tamaño de Colchane, [Chile]. Sábado por medio se hace una gran feria en el pueblo boliviano, donde se vende prácticamente de todo"90.

Esta lógica particular, resultado de prácticas informales y de la movilidad presente en la franja, supone valorizar áreas desestimadas o significadas bajo otra lógica por parte de los Estados ${ }^{91}$, primero por la geopolítica tradicional y hoy por el incremento del contrabando y el narcotráfico. En consecuencia, el espacio tarapaqueño, de una multi-territorialidad basada en una historicidad particular, en tanto región periférica, presenta un desafío al Estado chileno, pues estos territorios generan fricciones que son reflejo de la imaginación espacial que tiene la autoridad presente en la frontera y la que comienzan tener actores tradicionales y nuevos. Dentro de estos últimos, el municipalismo indígena ha generado un nuevo desafío al Estado chileno. Este nace a partir de la creación de la singular alianza entre municipios rurales indígenas de Chile, Perú y Bolivia en torno al proyecto Alianza estratégica Aymaras Sin Fronteras ${ }^{92}$.

Esta asociación surge en el contexto de la revalorización de los actores propios de la acción pública local, que amplían su margen de maniobra, lo que les permite hacer usos múltiples de su papel político-institucional ${ }^{93}$.También surge al alero de la ratificación de los países del Cono Sur del Convenio 169 de la OIT Sobre Pueblos Indígenas y Tribales, que posibilita un protagonismo internacional inusitado a distintos grupos indígenas que ven a través de su movilización internacional la posibilidad de reivindicar, dentro de otros aspectos, lo referido a los territorios ancestrales y sus usos.

\footnotetext{
${ }^{87}$ Judge, 2005, p. 88.

${ }^{88}$ Valencia, 2011, p.12.

${ }^{89}$ Mancano, 2012.

${ }^{90}$ Bazán, 2013, p. 19.

${ }^{91}$ Nuñez et al, 2013.

92 Ésta es una organización internacional sin fines de lucro, de carácter intermunicipal, creada el año 2001, que mediante la articulación y cooperación a través de las fronteras busca implementar políticas que fomenten el desarrollo de la comunidad en áreas como agricultura, infraestructura, pequeñas empresas, recursos naturales, energía, cultura, educación, salud y desarrollo económico.

${ }^{93}$ Rouviere, 2009.
} 
Así, este proyecto ha revalorizado el territorio andino que comprenden 51 municipios rurales a través de emprender una estrategia de desarrollo transfronterizo inédito, con una serie de consecuencias. Dentro de ellas destacamos el desplazamiento del sistema diplomático, el que ha debido adaptarse y tolerar esta intromisión en su agenda, con una serie de consecuencias territoriales e institucionales ${ }^{94}$. Esta configuración simbólica espacial, marcada por lo trasfronterizo en torno a la extensión de una red de municipios, también ha promovido que se levanten íconos territoriales ${ }^{95}$, que moldean la relación del hombre con el espacio ${ }^{96}$. En efecto, la revaloración de los circuitos turísticos transfronterizos integrados en torno al Camino del inca ${ }^{97}$, dan cuenta de esta renovada percepción del espacio, pues en su gestión participan municipios de los tres países, revalorizando una práctica ancestral que precede a sus respectivos Estados ${ }^{98}$. Esta revaloración patrimonial "actúa como una nueva forma de diferenciación territorial (dimensión clave de la práctica turística) otorgándole un nuevo valor al espacio" "99. Valor que es posible destacar desde una mirada transfronteriza de la gestión patrimonial.

Por otro lado, destacamos -a modo de conjetura- el papel que han jugado organizaciones como la Agencia de Cooperación Japonesa ${ }^{100}$, JICA, y Centro de Estudios de Política Internacional, CeSPI ${ }^{101}$, representantes de intereses de actores políticos y económicos de Japón e Italia, respectivamente, quienes inciden en la estructuración del espacio transfronterizo tarapaqueño en el contexto actual marcado por la globalización a partir de sus estrategias de

\footnotetext{
${ }^{94}$ Cornago, 2013.
}

${ }^{95}$ Dentro de los comités de frontera, la subcomisión municipios ha tomado un rol muy importante, sobre todo porque ha llamado la atención de los gobiernos regionales y nacionales, y en un tema de interés para organismos internacionales de cooperación. Dentro de ellos la Agencia de Cooperación del Japón (JICA) y la ONG italiana CeSPI. Estos organismos han financiado la iniciativa Aymaras Sin Fronteras

${ }^{96}$ Nuñez, 2012.

${ }^{97}$ Los Incas se expandieron rápidamente por el territorio formando un imperio que ocupó 4.000 kilómetros. Una red de caminos cubrió la costa occidental de América del Sur con centro en Cuzco (Ecuador, Perú, Bolivia, el Norte de Argentina y Chile). Se considera como año de inicio de la dinastía el 1.200 d.C. Los restos arqueológicos más representativo se encuentran en Machu Pichu.(Guerrero et al, 2011,p. 132)

${ }^{98}$ En efecto, en "el espacio andino se puede observar este proceso de construcción social y política en cuyo paisaje se reflejan las huellas de las distintas sociedades que intervinieron en su construcción, tal es el caso de la cultura precolombina y la cultura colonial"'.(Guerrero et al,2011,p. 130-131)

${ }^{99}$ Guerrero et.al, 2011, p. 130-131.

${ }^{100}$ Dentro de las actividades que han realizado en la región de Tarapacá se destaca el apoyo en materia de cooperación técnica a Aymaras Sin Fronteras. Tamayo ITO , Asesora en Formulación de Proyectos Sector Económico para JICA, en el marco de un seminario realizado por Aymaras Sin Fronteras en 2006 señaló a propósito de su motivación para cooperar con este proyecto de desarrollo trasnfronterizo que "a Japón le costó salir de la davastadora situación en que quedó después de la II Guerra Mundial; por lo tanto, ahora quiere ayudar a los países, grupos o personas que tengan este tipo de iniciativas (como este Seminario) para salir de la pobreza. Por eso, JICA busca ayudar a través de la cooperación técnica y no con financiamiento. (...) En cuanto a Chile JICA tiene una herramienta de Copeeración Sur Sur que quieren implementar. ¿Por qué? Porque Chile está considerado como un país avanzado y desarrollado en el tema de exportación y la idea es que a través de estas cooperaciones técnicas, Chile intercambie su back ground en el tema exportación a Perú, Bolivia e incluso, a Paraguay"En: Hoernig Carla (jueves, 23 de noviembre de 2006 ) Japón presente en Putre: \{ mensaje en un blog $\}$ Recuperado de: http://lagodeparinas.blogspot.com.es/2006/11/japn-presenteen-putre.html

${ }^{101}$ En el caso del Cespi, esta organización promovió el programa Fronteras Abiertas que se propone "activar procesos virtuosos de intercambio (norte-sur, sur-sur) para el desarrollo territorial de las áreas de frontera. Fronteras Abiertas opera actualmente en cuatro áreas de frontera : Bolivia-Chile-Perú, Ecuador Perú, Argentina-Brasil-Paraguay y El Salvador-Honduras-Nicaragua (Golfo de Fonseca). (Marteles, 2009). En el caso de la triple frontera donde participa Tarapacá, como indica Marteles (2009) las comunidades andinas que la conforman "han sido actores fundamentales para el programa Fronteras Abiertas desde que inició sus actividades en 2007. La Alianza Estratégica Aymaras Sin Fronteras, conformada por 57 municipios de Bolivia, Chile y Perú, es una plataforma desde la cual se están dando iniciativas de cooperación transfronteriza y esfuerzos de integración "desde abajo", nacidos directamente desde el territorio de frontera. La Alianza Estratégica es un interlocutor político clave, que a pesar de que sabe conversar con la cooperación internacional, no tiene la suficiente capacidad para insertarse con eficacia en los procesos de gobernanza del territorio transfronterizo" 
cooperación Sur- Sur y Norte Sur. Sobre todo, como dijimos al principio, que muchos actores transnacionales construyen estrategias de toma de posición dentro de los mecanismos de gobernación territorial de los lugares en los que invierten a través de la destrucción creativa ${ }^{102}$, en la medida que una perspectiva espacial particular ( en este caso foránea) puede barrer con las territorialidades existentes, para instalar nuevos modos de organización política, económica o cultural $^{103}$, según sus motivaciones del momento. Estas nuevas modalidades pueden instaurar nuevos límites y nuevos contornos, desafiando las espacialidades que le preceden.

Aunque, como señalan quienes encabezan el programa Fronteras Abiertas, a propósito de su intervención en los territorios en que se busca fortalecer la gobernanza transfronteriza: "Cada una de estas áreas tiene sus propias características y la lógica de intervención del programa está directamente vinculada a la madurez de los procesos de descentralización de los países y al contexto más o menos favorable en lo referente a la integración.” (Marteles, 2009)

\section{El Estado y su rol en la franja fronteriza: ¿apropiación de espacialidades?}

Para Zurbano ${ }^{104}$ con la globalización, los territorios buscan insertarse en la economía global preservando sus especificidades: sus opciones en cuanto al desarrollo de sus territorios, exaltando sus identidades y promoviendo sus bondades; no obstante es un proceso conflictivo, pues los Estados deben ajustarse a las demandas de las redes globales a expensas de estos territorios, y, lo que es más importante, imponiendo su propia forma de concebir el espacio. Además, en estos procesos de reconversión territorial, por la asimetría presente, no queda claro si estos nuevos actores contribuyen y comprenden su vínculo con lugares próximos de su propia espacialidad. Por ello, es discutible si aprecian el significado de las formas espaciales creadas por otros en la medida que buscan instalar nuevos modos de organización afín a sus intereses.

En este marco, aunque la franja fronteriza tarapaqueña adquiere una dinámica de integración y cooperación transfronteriza, también paralelamente demanda mayor control en la circulación de mercancías legales e ilegales. Es aquí donde se expresan estos nuevos modos de organización política.

Es así como surgen nuevos dispositivos de seguridad diseñados desde el Estado para el control de las fronteras, los que adquieren una particular importancia ${ }^{105}$. Es el caso del Plan Frontera Norte $^{106}$, una expresión de teichopolítica ${ }^{107}$ que reedita imaginarios normalizadores y monopólicos desde el Estado. También surgen barreras fitosanitarias más férreas, demandadas

\footnotetext{
${ }^{102}$ Harvey, 1985.

${ }^{103}$ Hevilla y Zusman, 2007.

${ }^{104}$ Zurbano, 2008.

${ }^{105}$ En efecto, en el actual gobierno de Sebastián Piñera, la agenda pública para la franja fronteriza de Tarapacá ha priorizado el Plan Frontera Norte inyectando para el $2012 \$ 10$ mil millones de pesos. Y, por otro lado, le ha quitado atribuciones administrativas a las URAI, Unidades de Relaciones Internacionales de los Gobiernos Regionales. Se debe tener en cuenta que la URAI del GORE de Tarapacá fue pionera en esta actividad y una de las más activas de Chile en el gobierno anterior. En concreto, ahora dependen de la Seremía de Planificación y dejan de ser una unidad dentro del organigrama del Gobierno Regional.

106 En octubre de 2011, el Presidente Piñera anunció el Plan Frontera Norte, orientado a detener amenazas no convencionales provenientes del crimen organizado, el tráfico de drogas y las migraciones ilegales presentes en la región de Tarapacá.

107 Teichopolítica, vocablo griego $\tau \varepsilon \imath \chi o \varsigma$ (teicho) significa "muralla", acuñado por Stéphane Rosière (2012) para referirse a una política de clausura de fronteras a través del levantamiento de barreras físicas, ya fueran empalizadas, alambradas o murallas de piedra. Históricamente sus fundamentos se asentaron en una política de seguridad. "Es decir, como una forma para protegerse de dos grandes amenazas: la militar y la migratoria”.(Rosiere,2012,p.158)
} 
por los socios firmantes de TLCs que ha suscrito Chile en la última década ${ }^{108}$.Conjeturamos que estas prácticas de control, más allá de que tienen por objetivo velar por el patrimonio fitosanitario del país ${ }^{109}$, en ocasiones rebasan este objetivo y se constituyen en expresiones basadas en teichopolítica: una expresión de miedo o rechazo a la alteridad, en la medida que el inmigrante es sospecho de emprender actividades delictivas ${ }^{110}$ en tanto otro, puesto que en el uso del espacio desde esta perspectiva la figura del "otro" es una parte central del imaginario del miedo aún en un contexto percibido como relativamente seguro ${ }^{111}$, como es el caso de un complejo fronterizo. Este miedo al otro, pese a la globalización y los discursos que enfatizan en la apertura, explican que el mundo sigue erigiendo barreras que controlan/separan a diversos colectivos humanos ${ }^{112}$. Chile y la franja fronteriza de Tarapacá no serían la excepción.

Esta preocupación especial por la frontera tiene su origen y justificación en la dinámica que ha adquirido el tráfico de drogas presente en Tarapacá, proveniente de dos de los mayores países productores de clorhidrato de cocaína y sus derivados: Perú y Bolivia ${ }^{113}$. En este marco, la seguridad amplía sus componentes, incorporando una nueva lógica de administración de la seguridad que reside sólo en el Estado como administrador de la fuerza de manera monopólica"114. Los gobiernos han "reclamado formas extraordinarias de autoridad y capacidad coercitiva a través de nuevas leyes, y la inyección de nuevos recursos humanos y materias,

${ }^{108}$ La homologación de barreras sanitarias entre las fronteras de Chile y Bolivia, ha sido siempre la piedra de tope para mejorar el funcionamiento de los respectivos servicios agrícolas ganaderos de forma integrada, SAG (Chile), SENASAG (Bolivia). Esto ha llevado al Estado chileno a recrudecer las barreras de forma unilateral para así controlar la "fiebre aftosa" en los bovinos; "mosca de la fruta" y "termitas" en insectos. No obstante, el discurso de la autoridad en torno a velar por el "patrimonio fitosanitario" se ve rebasado por conductas nacionalistas y xenófobas hacia los migrantes bolivianos al momento de controlarlos en la frontera.

${ }^{109}$ Por ejemplo, el blog boliviano "Bolivia, lo mejor que tenemos", dedicado a noticias vinculadas con Chile señala el 26 de mayo de 2011 lo siguiente: "El cerco de alambre de púas que puso Chile en una parte de la frontera con Bolivia, en el sector de Pisiga Bolívar (Oruro) entre los hitos 31 y 32, altera las buenas relaciones que había entre los bolivianos y chilenos que conviven en la zona, aseguró el cívico del lugar Williams Colque”. Prosigue Colque: ““‘E1 enmallado ha generado malestar y susceptibilidad de la gente porque históricamente hemos compartido los recursos naturales por un acuerdo verbal, es decir, por usos y costumbres". Seguidamente el blog explica las razones del cerco: "Estúpida explicación de Chile. Atribuye las mallas en la frontera con Bolivia al riesgo de la aftosa (...) El Gobierno chileno atribuyó hoy a ciudadanos particulares la colocación de mallas en la frontera con Bolivia y vinculó esos hechos con el riesgo de que algunos animales que se encuentran en territorio boliviano padezcan aftosa. "El informe que tengo es que corresponde a un enmallado para proteger a animales que tienen al otro lado, que pasan a este lado, y que tienen un peligro de aftosa", señaló el ministro chileno de Relaciones Exteriores, Alfredo Moreno" En: Danny, (26 de mayo de 2011) Bolivia, lo mejor que tenemos: "Cívicos de Pisiga advierten que cerco chileno altera la paz" \{ mensaje en un blogg\} Recuperado de: http://boliviateamo.blogspot.com.es/2011/05/civicos-de-pisigaadvierten-que-el.html

${ }^{110}$ Muchas veces el decomiso de productos es un acto arbitrario y discrecional, que depende de la voluntad del funcionario. Ejemplo de ello es el decomiso de pululos (cereal típico de los pueblos del altiplano chileno y boliviano que se vende en las festividades religiosas del norte de Chile. Son transportados de forma artesanal desde Bolivia) para la fiesta de la Tirana. Otros actos arbitrarios se vinculan al trato de la policía que tramita el ingreso de extranjeros en pasos fronterizos: "En Colchane a mucho que intentan cruzar la fronteras no se les ha permitido el ingreso por falta de una carta de invitación, insuficiente solvencia, o carencia de algún papel o sello. La sensación generalizada era de molestia y frustración por lo que ellas y ellos consideran un trato discriminatorio. Alegan que los requisitos para el ingreso no son claros y que varían de acuerdo al funcionario/a que los/as atienda: la solvencia puede ser de 500 o de 5000 dólares, a algunos les han requerido tarjeta de crédito. Cuando creen que han cumplido los requisitos exigidos, vuelvan al paso fronterizo y hay nuevas exigencias, o el funcionario/ia simplemente les dice que no los/as va a dejar entrar, "los negros no entran a Chile". (INDH,2013)Indican que estas arbitrariedades "van acompañadas de maltrato verbal por parte de la PDI: les tiran los pasaportes, los/as insultan ("negra muerta de hambre", "ustedes vienen a robar", "vayan a maraquear a otro lado". (INDH, 2013)

${ }^{111}$ Rodríguez,2008

112 Rosiere, 2012.

${ }^{113}$ Corder y Ruiz -Tagle, 2013.

${ }^{114}$ Aranda y Corder, 2013. 
especialmente tecnológicos"115. En este sentido, surge el Plan Frontera Norte a través de una plataforma que asegura mayores rangos de control de acceso a fronteras terrestres de Tarapacá sobre la base de implementación de tecnología más el concurso de diversas agencias estatales que se coordinan para compartir información ${ }^{116}$.

El referido programa supone mayor dotación de recursos humanos y físicos a las dos policías y a las Fuerzas Armadas con el objetivo de vigilar y seleccionar el tránsito de mercancías desde y hacia Chile, eliminando el ingreso de productos ilícitos (contrabando y drogas), aunque sin detener los flujos comerciales legales ${ }^{117}$.

Lo anterior implica el uso de tecnología no invasiva y portales de inspección de cargas de vehículos en pasos fronterizos y dispositivos fijos así como móviles de control para caminos, carreteras y sectores no habilitados para el tránsito vehicular aunque de hecho utilizados como zonas de paso. Restringiendo el ingreso y la circulación de drogas se pretende reducir la disponibilidad de sicoactivos.

No obstante, si bien este plan no contempla ninguna medida legalmente amparada que afecte el flujo migratorio, desafiando la espacialidad de los habitantes de la frontera, en la práctica se han implementado medidas, informalmente, que afectan su desarrollo. Es el caso de la decisión por parte de la Gobernación Provincial de Iquique de retener buses, para realizar controles de identidad, en sectores no previstos por la legislación vigente, en concreto fuera de los controles fronterizos. Se consideró por algunos sectores de la opinión pública como una medida arbitraria e inconstitucional, pues afectaba el libre tránsito. En efecto el Diario el 21 señala:

"En medio de la polémica por la idea de introducir un decreto, por parte de la Subsecretaría de Transportes y Telecomunicaciones, -para restringir el ingreso de vehículos de transporte internacional de Bolivia entre la medianoche y las ocho de la mañana, así como la incorporación de una segunda fiscalización para éstos en Huara-, el gobernador de Iquique, Felipe Rojas volvió ayer a salir a la palestra para aclarar y rectificar el "ruido" que ocasionó la propuesta en la opinión pública y parlamentarios." 118

Finalmente, otra forma de expresión de control más sutil constituye la apropiación de formas de imaginación geográfica propias de grupos subalternos por parte del Estado. Un ejemplo notable de esta práctica es la creación de "ferias ciudadanas" en la franja fronteriza de Tarapacá por parte del Estado. En ellas se da conocer a los habitantes de la franja su rol en dicho territorio:

"En Colchane parten ferias ciudadanas. En el gimnasio techado Fidel García, de Colchane, se a habitantes de los distintos poblados aledaños, quienes desde el mediodía podrán recibir orientación de distintas áreas de la administración pública. Para esto se contará con más de treinta servicios públicos y otras privadas para tramitaciones e informaciones anexas que maneja el Estado y que pueden ser de interés para los habitantes. Además se dictarán charlas para conocer el funcionamiento del Complejo Fronterizo Integrado, el control de plagas que aplica SAG y la Autoridad Sanitaria y las barreras fitosanitarias para mantener al país libre de la mosca de la fruta" $" 119$.

Esta feria ciudadana tiene la particularidad de apropiarse de una práctica tradicional fronteriza aymara y de su conciencia espacial, la que el Estado hace suya. El elemento más peculiar es que dicha feria solo se realiza en el territorio chileno allende la frontera, desconociendo la singularidad de las ferias originales: su carácter transfronterizo. Además surgen para prevenir contrabando e informalidad, dos prácticas propias de las ferias trasfronterizas. Así, en esta nueva

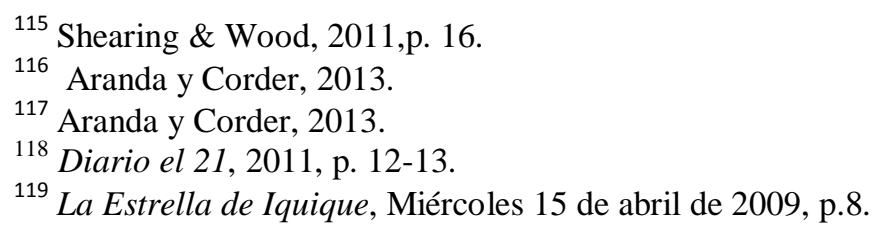


dinámica el Estado cobra un rol protagónico en la medida que emprende estrategias espaciales de manera discrecional, que en ocasiones desconocen otras formas identitarias paralelas:

"Esta será la primera de diez ferias ciudadanas que realizarán durante todo el año en las comunas del interior de la región, teniendo como segunda parada el 8 de mayo en Pisagua, en junio será el turno de Camiña y Matilla, al otro mes continuarán en La Tirana y Pachica, mientras que en agosto acudirán hasta Pica, siguiendo en septiembre con La Huayca, en octubre será en Huara y en noviembre cerrarán el ciclo con una gran fiesta ciudadana en las afueras de la gobernación, ubicada en Pozo Almonte" ${ }^{\text {"20. }}$.

Finalmente, otro ejemplo que ilustra esta fricción, lo recogemos de una entrevista emitida el mes de abril del presente año en el periódico La Tercera, en donde se refleja dicha forma antagónica de la vida cotidiana de la franja fronteriza, y como los actores oficiales la representan:

"Un grupo de carabineros sale a patrullar (...) ya nadie sale sin un policía que conozca muy bien la zona y los límites de la frontera. No podemos arriesgarnos a pasarnos ni un metro hacia el lado boliviano".

Cada carabinero en la frontera ocupa fusiles de guerra, en caso de que las cosas se compliquen. El camino llega a su fin. A un lado hay cerros chilenos y al otro lado, el salar, que es casi totalmente boliviano. Un poco más allá de uno de los hitos que marca la línea imaginaria de la frontera hay un puesto de avanzada del Ejército boliviano con capacidad para unas 12 personas, según los carabineros. A diferencia de Chile, donde es la policía la que se encarga del patrullaje fronterizo, en Bolivia los encargados de esta tarea son los militares. El teniente Tapia y el cabo Cofré avanzan hasta el hito para asegurarse de que no haya sido movido.

-¡Hasta ahí no más! -les grita el teniente coronel Hugo Zenteno, quien mira atento que nadie salga del refugio militar boliviano $^{121}$.

Estas prácticas reflejan la creciente percepción de la frontera por parte de las policías que la controlan como un lugar soberano, el que hay que "cuidar". En suma, estas prácticas se interpretan desde la gubernamentalidad ${ }^{122}$. Puesto que esta categoría designa todo un entramado de formas de hacer y pensar que tiene por objeto, sobre la base de una serie de dispositivos de seguridad, el ordenamiento de la población, donde adquiere una relevancia importante ordenar el espacio a partir de preservar la soberanía estatal.

No obstante, pese la pretensión estatal por normalizar este espacio ${ }^{123}$, desde el giro teórico que hemos propuesto, también destacamos que las fronteras se encuentran presente nuevos y viejos movimientos y dinámicas territoriales, en la medida que - como ya hemos señalado- las fronteras que demarcan las comunidades domésticas no son naturalmente dadas, indudables ni permanentes, toda vez que están sujetas a una serie de transgresiones ${ }^{124}$. Estas transgresiones, que cuestionan la territorialización que hace el Estado de las fronteras a través de políticas de contención territorial $^{125}$ (Plan Frontera Norte, fronteras sanitarias, dentro de otras políticas), se abren hacia subjetividades no estatales, como es el caso de grupos étnicos, elites económicas y gobiernos subnacionales, quienes propician "otras voluntades de desterritorialización," ${ }^{126}$ las que

${ }^{120}$ La Estrella de Iquique, Miércoles 15 de abril de 2009, p.9.

${ }^{121}$ Bazán, 2013,p. 19.

${ }^{122}$ Foucault, 2006.

${ }^{123}$ Nuñez, 2012

${ }^{124}$ Weber, 1995:109

${ }^{125}$ Contención territorial, entendida como "un proceso contemporáneo de las relaciones de poder referidas al espacio, donde se dibujan nuevas-viejas estrategias de control territorial; y digo "nuevas-viejas", porque en nuestros días los muros son más visibles y evidentes que nunca, pero al mismo tiempo constituyen una estrategia muy antigua de construcción territorial"( Haesbaert,2013,13).

${ }^{126}$ Cornago, 2013b 
a su vez tienen sus propios imaginarios geográficos que, en nuestro caso, no coincidentes con los imaginarios estatales.

Por tanto, la soberanía del Estado, que define las fronteras físicas de los estados y que cautela férreamente el espacio circundante que contiene, es "un elemento delimitador tan importante como inestable, pues la territorialización a la que aspira nunca es completa. Siempre se le oponen otras voluntades de des-territorialización"127. Aunque las políticas de contención territorial, que han afectado a dichas subjetividades han sido una constante en la historia de Tarapacá.

\section{Conclusiones}

Intentamos interpretar cómo la fijación del sentido territorial del Estado nacional hegemónico, heredado desde la geopolítica tradicional, se renueva con la lógica de la securitización. Se trata de discursos y prácticas que tienen una continuidad que, por su marcada historicidad, es decir, su legitimación discursiva a través del tiempo, reflejan interpretaciones territoriales reificadas ${ }^{128}$. En concreto, como hemos visto más arriba, se trata de dispositivos fitosanitarios y nuevas barreras de seguridad que afectan el comercio de los habitantes transfronterizos y su normal desenvolvimiento cotidiano en la frontera, relegando otras opciones espaciales, junto con la vigencia de una memoria marcada por la geopolítica tradicional de frontera. Para Walker ${ }^{129}$, estos dispositivos son destinados a justificar la existencia del Estado entendido como el espacio de la identidad y unidad. Con ellos, aquel, en tanto portador de identidad nacional, se une a la subjetivación de cada individuo, imbricándose.

En cuanto a la apropiación territorial y la espacialidad presente en la franja tarapaqueña, destacamos la presencia de modelos de ordenamiento y uso del espacio desde el Estado que enfatizan en el control, la seguridad y la soberanía desde una forma renovada por la securitización e implementada a través del Plan Frontera Norte.

Por otro lado, la autoridad tiene una concepción de la población migrante, en algunas ocasiones cargadas de estereotipos y rechazo debido al contrabando y el narcotráfico.

En cuanto a la percepción oficial del espacio fronterizo y las prácticas de resistencia y adaptación presentes en nuestro territorio estudiado, podemos pensar que la movilidad propia de los migrantes se constituye en el hacerse y deshacerse del espacio en el modo en que se practica, las formas en las que se ordena, las conexiones que se $\operatorname{trazan}^{130}$. Así, los habitantes trasfronterizos, conscientes del abandono y de sus necesidades, cruzan la frontera de manera constante y construyen realidad en virtud de las oportunidades que se les manifiestan a uno y otro lado. Junto con ello, las redes de cooperación entre ambos países como es el caso del proyecto estratégico Aymaras Sin Fronteras, suponen una imaginación común a la hora de instaurar territorio.

\footnotetext{
${ }^{127}$ Cornago, 2013b

${ }^{128}$ Nuñez, 2012

${ }^{129}$ Walker, 2010

${ }^{130}$ Mendiola, 2012
} 
Respecto a las limitaciones de nuestro trabajo, destacamos la referida a que al aproximarnos de forma dicotómica a esta franja fronteriza - desde la pugna entre imaginarios nacionales y locales-, no consideramos la presencia de otras territorialidades móviles en construcción. Nos referimos a la presencia de ciertos imaginarios geográficos coincidentes en la franja de Tarapacá, que tienen su origen en prácticas colaborativas entidades estatales y de la sociedad civil. Es el caso de los actores que promueven algunos proyectos de integración transfronteriza en torno a la construcción de corredores bioceánicos, que en su trazado Tarapacá es clave. Estimamos que estas opciones relativizan los resultados de nuestro trabajo, particularmente en lo referido a la tendencia a la monopolización del espacio fronterizo por parte del Estado.

Finalmente, consideramos que en el juego cultural presente en la franja fronteriza de Tarapacá se encuentra una diversidad de imaginarios geográficos, que nos permiten expresar las diferencias y además nos obliga a plantear nuevas regulaciones en torno a que se debieran adecuar a las diversas representaciones espaciales presentes en este territorio.

\section{Bibliografía}

AMILHAT SZARY, Anne-Laure. Regiones ganadoras y regiones perdedoras en el retorno de la democracia en Chile: poderes locales y desequilibrios territoriales, EURE, 1997, vol. 23, nº 70, p. $59-78$

AMILHAT SZARY, Anne-Laure. Minas en la montaña: Cuando la explotación de las periferias escapa al Estado. En, Andrés Núñez - Rafael Sánchez - Federico Arenas (edit). Fronteras en movimiento e imaginarios geográficos La cordillera de Los Andes como espacialidad sociocultural.Santiago de Chile: Instituto de Geografía, Pontificia Universidad Católica de Chile, RIL.2013, p. 221-242.

ARANDA Gilberto; CORDER, Alejandro. Plan Frontera Norte: ¿expresión de teichopolítica? Trabajo presentado en V Jornadas de Historia de las Relaciones Internacionales, Valparaíso : Centro de Estudios Latinoamericanos - CEL Instituto de Historia y Ciencias Sociales - Facultad de Humanidades, Universidad de Valparaíso., 4, 5 y 6 de septiembre de 2013

BAILLY, Allan. Distances et espaces: vingt ans de géographie des représentations. L'Espace géographique, 1985 , no 3, p.197, 205

BAZÁN, Ignacio. Arde la frontera. El semanal. La Tercera, edición impresa [domingo 21 de abril de 201], p. 18-21.

BENEDETTI, Alejandro. Espacios fronterizos del sur sudamericano. Propuesta de un modelo conceptual para su estudio Estudios Fronterizos, 2014, vol. 15, n 29, p.11-47.

BRENNA, Jorge. La mitología fronteriza: Turner y la modernidad. Estudios fronterizos, 2011, vol. 12, n²4, p. 9-34.

CAMAÑO, Carmen. Espacios de gubernamentalidad entre el "centro" y la "periferia": definiendo la migración y el desarrollo en la zona de los santos. Revista Reflexiones, 2012, vol. 91, n 1, p. 177-190.

CAMUS, Pablo y ROSENBLITT, Jaime. Aislamiento de la frontera norte de Chile: ¿problema u oportunidad? Un análisis histórico, 1880-1990 En: Federico Arenas, Alejandro Salazar y Andrés 
Núñez. El aislamiento geográfico: ¿problema u oportunidad? Experiencias, interpretaciones y políticas públicas. Santiago: Serie geo libros, 2011, p. 59-73.

COHELO, Jose. Límites e paradoxos da cidadania no territorio fronteirico: $\mathrm{O}$ atendimento dos brasiguaios no sistema público de saude em Foz do Iguacu (Brasil). Geopolítica(s). Revista de estudios sobre espacio y poder, 2013, vol. 3, nº. 2, p. 185-205.

CONNOLLY, William. The Ethos of Pluralization. Minneapolis, London: University of Minnesota Press. 1995

CORDER, Alejandro y Ruiz Tagle, Viena Infracciones penales en espacios transfronterizos. El narcotráfico en la provincia del Tamarugal, Chile. Estudios Fronterizos, 2013, vol. 14, nº. 27, p. $31-63$

CORNAGO, Noé. Plural Diplomacies: Normative Predicaments and Functional Imperatives. Amsterdam: Martinus Nijhoff Publishers, 2013.

CORNAGO, Noé Breviario de postestructuralismo para internacionalistas, en: http://www.academia.edu/2286259/Breviario_de_postestructuralismo_para_internac Ionalistas, $2013 \mathrm{~b}$

DAMMERT, Lucía y Bailey, John. Reforma policial y participación militar en el combate de la delincuencia. Análisis y desafíos para América Latina. Revista Fuerzas Armadas y Sociedad. 2005, vol. 19, nº 1, p. 133-152.

DEBUYST, Fréderic. Lógicas y sentidos de los enfoques territoriales, Revista Polis, 2009, vol., 8, $\mathrm{n}^{\mathrm{o}} 22$, p. 21-37.

DE CASTRO, Constancio. Tras la búsqueda de la europeidad. Mapas mentales de Europa conforme a la memoria social de los europeos Geocrítica. Scripta Nova. Revista Electrónica de Geografía y Ciencias Sociales 2001, № 91http://www.ub.edu/geocrit/sn-91.htm [ISSN: 1138-9788]

Diario el 21 "Gobernador Rojas propone socializar "fiscalización amigable" a buses bolivianos", Marzo 28, 2011, , Iquique, Chile, p.11-12

DONOSO, Carlos. Debates y reflexiones en torno a la crisis económica en Tarapacá (1934-1953): notas preliminares. Revista de Historia Social y de las Mentalidades, 2009, $\mathrm{n}^{\mathrm{o}}$ 13, vol. 2, p. 9-42

ESKELINEN, Heikki. Formas volátiles y sostenibles de interacción como conductores de cambio en regiones fronterizas en el Norte Europeo. Si Somos Americanos. Revista de Estudios Transfronterizos, 2010, vol. 11, $\mathrm{n}^{\mathrm{o}}$ 2, p.123-138.

FERNANDEZ, Francisca. Etnicidad y ciudadanía indígena: las formas de acción colectiva aymara en Argentina, Bolivia, Chile y Perú. Si Somos Americanos. Revista de Estudios Transfronterizos, 2009, vol. 9, nº 2, p. 31-44.

FERNANDOIS, Joaquín. Mundo y fin de mundo: Chile en la política mundial 1900-2004”. Santiago: Ediciones Universidad Católica de Chile, 2004. 
FERNANDOIS, Joaquín y León Hulaud. ¿Antonimia entre democracia y gobierno militar? Chile y Argentina en el momento de incertidumbre (1955 -1973). En: Lacoste, Pablo (editor), Argentina, Chile y sus Vecinos, Tomo II. Mendoza-Argentina: Caviar Bleu, 2005, p. 93-141.

FOUCAULT, Michel. Governmentality. En: G. Burchell, C. Gordon y P. Miller (Eds.). The Foucault effect. Studies in governmentality. Chicago, CA: The University of Chicago Press. 1991, p.87-104.

FOUCAULT, Michel. Microfísica del poder. Madrid: La Piqueta. (Primera 1978), 2002.

GIMENEZ, Gilberto. Cultura, identidad y memoria: Materiales para una sociología de los procesos culturales en las franjas fronterizas. Frontera norte, 2009, vol.21, no 41, p. 7-32

GIMÉNEZ, Verónica. La "triple frontera" y sus representaciones: Políticos y funcionarios piensan la frontera. Frontera norte, 2011, vol. 23, no 46, p. 7-34.

GOBIERNO DE CHILE, Ministerio del interior, Instituto Nacional de Derechos Humanos, INDH, Misión de Observación Iquique y Colchane: "Informe misión de observación situación de la población migrante Iquique y Colchane”, 29 a 31 de mayo de 2013, Iquique, región de Tarapacá, Chile.

GOBIERNO DE CHILE, Ministerio de Economía, Instituto Nacional de Estadística, INE. Censo de población. Santiago de Chile, 2012.

GONZÁLEZ, Sergio. Chilenizando a Tunupa. La escuela pública en el Tarapacá Andino 1880 1990. Santiago de Chile: DIBAM. 2002.

GONZÀLEZ Miranda, Sergio. La sociedad del salitre: Protagonistas, migraciones, cultura urbana y espacios públicos. Santiago de Chile: RIL ediciones. 2013.

GONZÁLEZ, Sergio, ROUVIERE, Laetitia, OVANDO, Cristian. De Aymaras en la frontera" a "Aymaras sin fronteras. Los gobiernos locales de la triple-frontera andina (Perú, Bolivia y Chile) y la globalización. Diálogo Andino, 2008, nº 31, p. 31-46.

GUERRERO, Ana Lía.; GALLUCCI, Soledad Paula.; MICHALIJOSNY, Stella.; MARIS, Visciarell. Países Andinos: aportes teóricos para un abordaje integrado. Huellas, 2011, nº 1520. p. 121-138.

HAESBAERT, Rogerio. "Del mito de la desterritorialización a la multiterritorialidad". Revista Cultura y Representaciones Sociales, 2013, n. 15., p. 9-41.

HARVEY, David. Urbanismo y desigualdad social. Madrid: Siglo XXI, 1985.

HEVILLA, Cristina y ZUSMAN, Perla. Diez años de estudios de fronteras en los coloquios internacionales de Geocrítica. Scripta Nova. Revista Electrónica de Geografía y Ciencias Sociales 2008, vol. XII, núm. 270 (150). <http://www.ub.es/geocrit/sn/sn-270/sn-270-150.htm> [ISSN: 1138-9788]

HEVILLA, Cristina.; ZUSMAN, Perla. Movilidades y construcción de nuevas territorialidades en la frontera chileno-argentina. Scripta Nova. Revista Electrónica de Geografía y Ciencias Sociales, 2007,vol. XI, n 245. <http://www.ub.es/geocrit/sn/sn-24522.htm> [ISSN: 1138-9788] 
HEVILLA, Cristina y MOLINA, Matías. La ciudad de San Juan: imaginarios de las reconstrucciones inconclusas. Scripta Nova. Revista Electrónica de Geografía y Ciencias Sociales. 2010, vol. XIV, $\mathrm{n}^{\circ} 331$ (78). <http://www.ub.es/geocrit/sn/sn-331/sn-331-78.htm>. [ISSN: 1138-9788].

JUDGE, Lionel. Más allá del estado-nación en Bolivia: Una sociedad de comerciantes el ejemplo del comercio transfronterizo con Chile. En, Corder Tapia, Alejandro (editor). VI Seminario Internacional de Integración Sub-Regional: Sociedades de frontera, montaña y desierto. Iquique: Ediciones Instituto de Estudios Internacionales; Universidad Arturo Prat, 2007, p.86-90.

LEFEBVRE, Henri. La production de l'espace. Paris: Anthropos.1974.

LEIVA, Sandra. La subcontratación en la minería en Chile: elementos teóricos para el análisis. Polis, 2009, vol.8, nº.24, p. 111-131.

LOIS, Carla .La invención del desierto chaqueño. Una aproximación a las formas de apropiación simbólica de los territorios del chaco en los tiempos de formación y consolidación del estado nación argentino. Scripta Nova. Revista Electrónica de Geografía y Ciencias Sociales, 1999 N $^{\circ}$ 38. http://www.ub.edu/geocrit/sn-38.htm\#N_1_

MACHADO, Horacio. Identidades en conflicto. Reconversión neocolonial, conflictos socioterritoriales y procesos de subjetivación en un contexto periférico del capitalismo global. Boletín Onteaiken, 2009, $\mathrm{n}^{\circ} 7$.

MANCANO, bernardo. Movimentos socioterritoriaris e movimentos socioespaciais" Revista del Observatorio Social de América Latina, 2006, nº VI. , vol.16.

MARTELES, Silvia. "Fortalecimiento de la gobernanza transfronteriza en América Latina a través de la cooperación descentralizada: La experiencia del programa Fronteras Abiertas". En: BRIT, X Congreso de las Regiones Fronterizas en Transición: Fronteras del Cono Sur de América y fronteras del mundo. Estudios en torno a lo global/local. Mayo $25 \& 26$ (Arica, Chile) - Mayo 27 \& 28 (Tacna, Perú), 2009.

MEDINA, Eusebio. Aportaciones para una epistemología de los estudios sobre fronteras internacionales .Estudios Fronterizos, 2006, vol. 7, n¹3, p. 9-27.

MENDIOLA, Ignacio. Regímenes de movilidad y domesticación del espacio. Revista Política y sociedad, 2012, vol.49, $\mathrm{n}^{\circ} 3$.

MUSSETTA, Paula. Foucault y los anglofoucaultianos: una reseña del Estado y la gubernamentalidad. Revista Mexicana de Ciencias Políticas y Sociales, 2009, vol. LI, n²05, p. $37-55$.

NIETO, Diego. Una democracia agonística para sociedades en conflicto: La defensa del pluralismo radical. Ponencia Presentada en el marco del I Seminario Internacional Conflicto y Democracia realizado por la Universidad del Magdalena 17 - 19 de Noviembre 2010.

NÚÑEZ, Andrés. El país de las cuencas: fronteras en movimiento e imaginarios territoriales en la construcción de la nación. Chile siglos XVIII-XIX. Scripta Nova. Revista Electrónica de Geografía y Ciencias Sociales, 2012, vol. XVI, nº 418.

NÚÑEZ, Andrés.; ARENAS.; Federico. SABATINI, Francisco. Producción de fronteras e imaginarios geográficos: de la nacionalización a la globalización de la Cordillera de los Andes. 
Chile, siglos XX y XXI. En, Fronteras en movimiento e imaginarios geográficos La cordillera de Los Andes como espacialidad socio-cultural. 2013. Instituto de Geografía, Pontificia Universidad Católica de Chile, RIL, Santiago.

OVANDO, Cristian.; ÁLVAREZ, Gonzalo. La dimensión fronteriza de la política exterior de Chile: inmovilidad y emergencia de nuevas dinámicas. Estudios Fronterizos, Nueva Época, 2012, vol. 12, n 24, p.75-102.

OVANDO, Cristian La seguridad internacional en la proyección de Chile hacia el Cono Sur: ¿desde La Doctrina de la Seguridad Nacional hacia La construcción de Comunidades de Seguridad o la emergencia de La Securitización?, Revista de Relaciones Internacionales, Estrategia y Seguridad, 2012, vol. 7, no 2, p.193-219.

RODRÍGUEZ, Gabriela. El miedo al otro y el uso del espacio: el discurso sobre el delito y el conflicto en la ciudad de Lérida. Scripta Nova. Revista Electrónica de Geografía y Ciencias Sociales.2008, vol. XII, núm. 270 (16). 〈http://www.ub.es/geocrit/sn/sn-270/sn-270-16.htm> [ISSN: 1138-9788]

ROUVIERE, Laetitia ¿Un territorio político transfronterizo? Formas de legitimación de una experiencia de legitimación de una experiencia de acción política intermunicipal, Si Somos Americanos. Revista de Estudios Transfronterizos, 2009, vol. 2, nº 9, p.13-29.

RAMOS, Romina; URBINA, Danae. Percepción de las mujeres inmigrantes usuarias de la Pastoral de Migraciones INCAMI-IQUIQUE, en cuanto a su vinculación con las redes de apoyo en la región de Tarapacá, durante el segundo semestre del año 2011. (Tesis inèdita) Universidad Arturo Prat, Iquique.

RODRIGUES, Thiago. Agonismo y genealogía: hacia una analítica de las Relaciones Internacionales. Relaciones Internacionales, 2013, n ${ }^{\circ} 24$, p.89-107.

ROSIÈRE Stéphane "teichopolitics: thepolitics of borderclosure" Si Somos Americanos. Revista de Estudios Transfronterizos, 2012, vol. XI, n ${ }^{\circ}$, p.151-163.

SHEARING, Clifford; WOOD, Jennifer. Pensar la seguridad, Barcelona: Gedisa.2011.

TAPIA, Marcela. Frontera y migración en el Norte de Chile a partir del análisis de los censos de población. S. XIX y XXI Revista Geografía Norte Grande. 2012. n 52, p.177-198.

TAPIA, Marcela.; OVANDO, Cristian. Los Andes tarapaqueños, nuevas espacialidades y movilidad fronteriza, ¿barrera geográfica o espacio para la integración? En, Andrés Núñez Rafael Sánchez - Federico Arenas (edit). Fronteras en movimiento e imaginarios geográficos La cordillera de Los Andes como espacialidad socio-cultural, 2013., Instituto de Geografía, Pontificia Universidad Católica de Chile, RIL, Santiago, p.243-274.

TAPIA Marcela, RAMOS, Romina. Mujeres migrantes fronterizas en Tarapacá a principios del

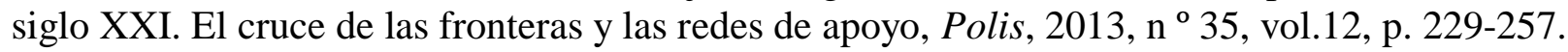

VALENCIA, Manuel. Los pueblos atrapados por el contrabando. La Tercera, edición impresa, [Lunes 27 de junio 2011].

VAN KESSEL, Juan. Los aymaras bajo el Régimen Militar de Pinochet (1973-1990). Cuaderno de Investigación Social, 1990, $\mathrm{n}^{\circ}$ 29, p.170-186 
WALKER, Rob. After the Globe, before the World, London. New York, Routledge, 2010.

WEBER, Cynthia. "Simulando Soberanía: Intervención, El Estado e intercambio simbólico". En: NASI, Carlos (comp.): Postmodernismo y relaciones internacionales, Pontificia Universidad Javeriana ediciones, Colombia, 1995, p. 83-121, p 109.

WIMMER, A. y SCHILLER, N. G. Methodological Nationalism, the Social Sciences, and the Study of Migration: An Essay in Historical Epistemology. International Migration Review, 2003, $\mathrm{n}^{\circ} 37$, vol. 3, p. 576-610.

ZUSMAN, Perla. La geografía histórica, la imaginación y los imaginarios geográficos. Revista de Geografía Norte Grande, 2013, n54, p.51-66.

ZURBANO, Mikel. Las regiones como sujetos de la economía global. Ekonomiaz, 2008, $n^{\circ}$ 58, p.196-229.

(c) Copyright Cristian Ovando Santana, 2016

(c) Copyright Romina Ramos Rodríguez, 2016

(c) Copyright Scripta Nova, 2016.

Ficha bibliográfica:

OVANDO SANTANA, Cristian y RAMOS RODRIGUEZ, Romina. Imaginarios geográficos en torno a la franja fronteriza de Tarapacá: el estado y los habitantes/migrantes. Scripta Nova. Revista Electrónica de Geografía y Ciencias Sociales. [En línea]. Barcelona: Universidad de Barcelona, 1 de febrero de 2016, vol. XX, no 529. <http://www.ub.es/geocrit/sn/sn-529.pdf>. ISSN: 1138-9788. 